\title{
Non-invasive diagnosis of internal carotid artery dissections
}

\author{
W Müllges, E B Ringelstein, M Leibold
}

Department of Neurology, Klinikum der RWTH, Aachen W Müllges

E B Ringelstein

$M$ Leibold

Correspondence to: Dr Müllges, Neurologische Klinik, Klinikum der RWTH, Pauwelsstraße, D5100 (W) Aachen, Germany. Received 5 December 1990
and in revised form 28 May 1991

Accepted 11 June 1991

\begin{abstract}
Arteriography is thought to be mandatory for the diagnosis of internal carotid artery (ICA) dissection. With the introduction of transcranial Doppler sonography (TCD) and magnetic resonance imaging (MRI), however, this is no longer the case. In 13 consecutive patients with ICA dissections the diagnosis was made by means of non-invasive tests including extracranial and transcranial Doppler sonography, contrast enhanced computed tomography (ceCT), and, in five patients, MRI. Intra-arterial digital subtraction angiography used as the gold standard in all cases was confirmative. Extracranial and transcranial ultrasound findings indicative of the diagnosis could be identified. MRI directly demonstrated the intramural haematoma and the false lumen of the dissected artery. These noninvasive techniques also allowed for repetitive follow up examinations. They were, however, unable to demonstrate false aneurysms in the chronic state. Results show that the diagnosis of carotid dissection can be made by means of cerebrovascular ultrasound and $M R I$.
\end{abstract}
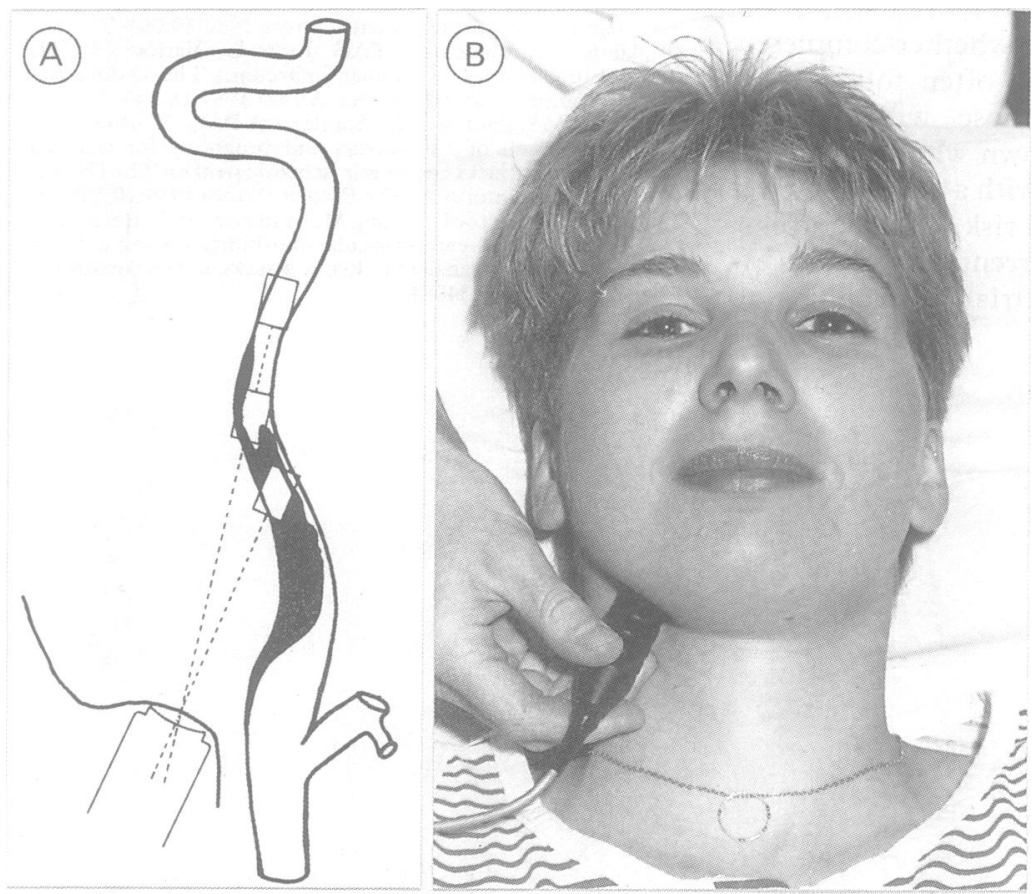

Figure 1 Submandibular approach to distal internal carotid artery by transcranial Doppler sonography. (a) Schematic diagram of dissected ICA. Probe is placed in submental triangle. Three different positions of sample volume are shown (black silhouette indicates false lumen). (b) Practical application.
Spontaneous dissecting aneurysms of the internal carotid artery (ICA) and other brainsupplying arteries are an essential cause of acute stroke $(1 \%)$ particularly in the young $(5 \%) .{ }^{1}$ Clinical signs leading to the diagnosis are well known. ${ }^{1} \mathrm{Up}$ to now, cerebral intraarterial angiography was thought to be mandatory for diagnosing dissecting aneurysms, ${ }^{1-3}$ while only a few reports referred to the noninvasive diagnosis of ICA dissections by means of ultrasound Doppler sonography, ${ }^{4-10}$ contrast enhanced computed tomography (ceCT) $)^{311-14}$ and magentic resonance imaging (MRI)..$^{10} 121516$ In the past three years we have used these noninvasive methods in 13 consecutive patients with ICA dissections to make the initial diagnosis and to perform close-meshed follow up studies and compared these findings with those of subsequent intra-arterial selective cerebral arteriography. This was done to evaluate noninvasive techniques by the conventional gold standard and to clarify how far angiography may be dispensable.

\section{Patients and methods}

Clinical evaluation-History of premonitory complaints and clinical findings were evaluated on admission, and outcome was checked for at least three months. The longest observation period was 28 months after the stroke. Characteristic clinical signs for presumptive diagnosis were ischaemic strokes, either transient or completed, and accessory symptoms due to direct damage of neighbouring structures by the dissected vessel wall such as carotidynia, ipsilateral head pain, Horner's syndrome, cranial nerve lesions, and pulsatile tinnitus.

Sonography-All ultrasound examinations were done before arteriography-that is, investigators were not aware of the final diagnosis. Extracranial cw-Doppler sonography of all brain-supplying arteries in the neck was performed initially in 11 of the 13 patients with a zero-crossing flowmeter with a bidirectional $4 \mathrm{MHz}$ Doppler device (Delalande $\mathrm{D}-800^{\mathrm{R}}$ ). In 10 patients, an initial transcranial pulsed Doppler ultrasound examination was also performed (EME TC 2-64 ${ }^{\mathrm{R}}, 2 \mathrm{MHz}$ ) with insonation of the retromandibular ICA segment from a submandibular approach (fig 1), transorbital insonation of the carotid siphon, and transtemporal access to the middle, anterior, and posterior cerebral arteries (MCA, ACA, PCA), as well as the very distal part of the ICA (C1segment). Transcranial insonation of the vertebrobasilar system from suboccipital 
Table Initial and follow up laboratory findings in 13 patients with internal carotid artery dissection

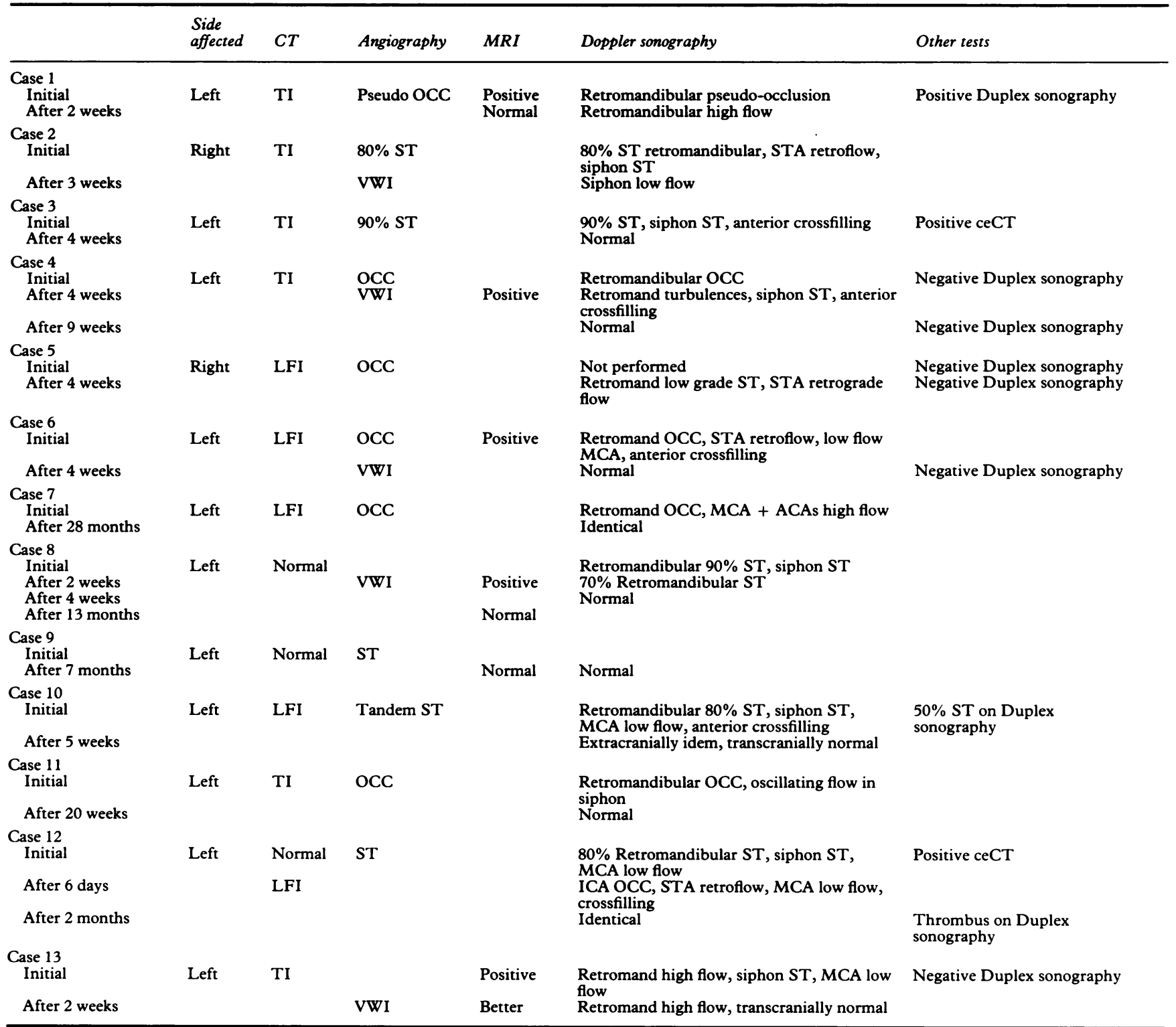

$\mathrm{TI}=$ territorial type of brain infarction.

VWI $=$ vessel wall irregularity.

ST/OCC = stenosis/occlusion

ceCT $=$ contrast enhanced CT

LFI $=$ low flow induced brain infarction.

MCA/ACA/PCA = middle/anterior/posterior cerebral artery

STA $=$ supratrochlear artery.

Retromand = retromandibular.

approach was also performed. Methodological details of these techniques are published elsewhere. ${ }^{716}{ }^{17}$ Abnormal flow was diagnosed if flow velocities were either two standard deviations lower or higher than normal values. ${ }^{16}$ In five patients B-mode imaging of the carotid bifurcation and proximal segment of the ICA was also performed (Biosound 2000 SA $^{\mathrm{R}}$, $7 \cdot 5 \mathrm{MHz}$ ).

Intra-arterial angiography was performed in all cases, in 11 on admission and in two after two weeks. The common carotid artery was catheterised selectively via a transfemoral approach. The injection volume of a non-ionic contrast medium was 5 to $7 \mathrm{ml}$. At least two views of the carotid axis were imaged on digital subtraction angiograms. In each case, a biplane vertebrobasilar imaging series was also perfor- med by selectively injecting into the left $(10)$ or right (3) vertebral artery.

Cranial computed tomography (CT) was done in every patient with a Somatom DRH-scanner $\left(\right.$ Siemens ${ }^{\mathrm{R}}$, matrix $\left.512 \star 512\right)$. The infratentorial slice thickness was $4 \mathrm{~mm}$ and $8 \mathrm{~mm}$ supratentorially. Contrast enhancement was used to visualise the carotid artery with its bifurcation and the siphon. ${ }^{11-13}$ Cerebral infarctions visible on CT were categorised according to a classification system recently published elsewhere. ${ }^{17-19}$ Territorial infarcts, which were thought thromboembolic in origin and haemodynamically caused low flow infarcts, were differentiated.

$M R I$ with visualisation of the cervical ICA was performed in six patients (Siemens Magnetom $^{R}$, $\left.1.5 \mathrm{~T}\right)$. Images were $\mathrm{T} 1-$ and 


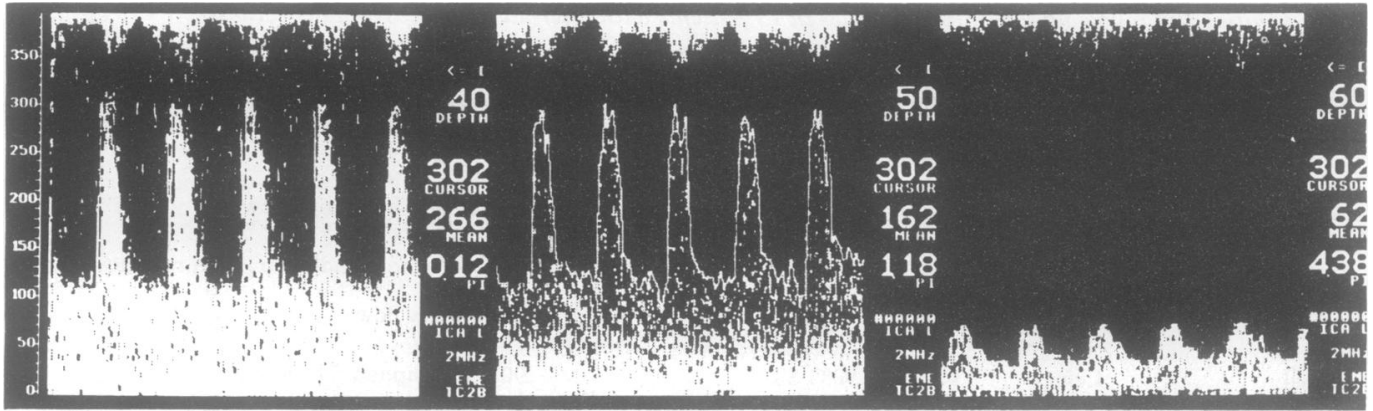

Figure 2 Typical transcranial Doppler sonographic finding in ICA dissection. Left and middle: submandibular insonation reveals high flow velocities (266 and $162 \mathrm{~cm} / \mathrm{s}$ ) at 40 and $50 \mathrm{~mm}$ insonation depths, indicating high grade stenosis. Right: poststenotic low flow $(62 \mathrm{~cm} / \mathrm{s})$ at $60 \mathrm{~mm}$ depth.

proton-weighted, as well as T2-weighted. Slice thickness was $5 \mathrm{~mm}$ without gap. The internal carotid artery was visualised transversally and also longitudinally.

Sonographic follow up investigations were performed in 12 of the 13 cases by extracranial and transcranial Doppler sonography. In six cases, repeat arteriograms or repeat MRI or both were also taken.

\section{Results}

PATIENTS AND CLINICAL SIGNS

Five women and eight men (mean (range) age $46(20-58)$ years with isolated unilateral dissection of the left (12) and right (1) ICA were included in the study. Four patients had suffered an unequivocal whiplash injury of the neck or a slight trauma without direct involvement of head and neck one to nine days before the occurrence of suggestive clinical symptoms. In the nine other patients dissections had occurred spontaneously. Vascular risk factors were present in eight cases; five were smokers, two women took contraceptive pills, and one had diabetes mellitus. Three patients had two vascular risk factors; three had common migraine.

Clinical signs and symptoms were quite variable. Six patients had suffered a complete stroke,
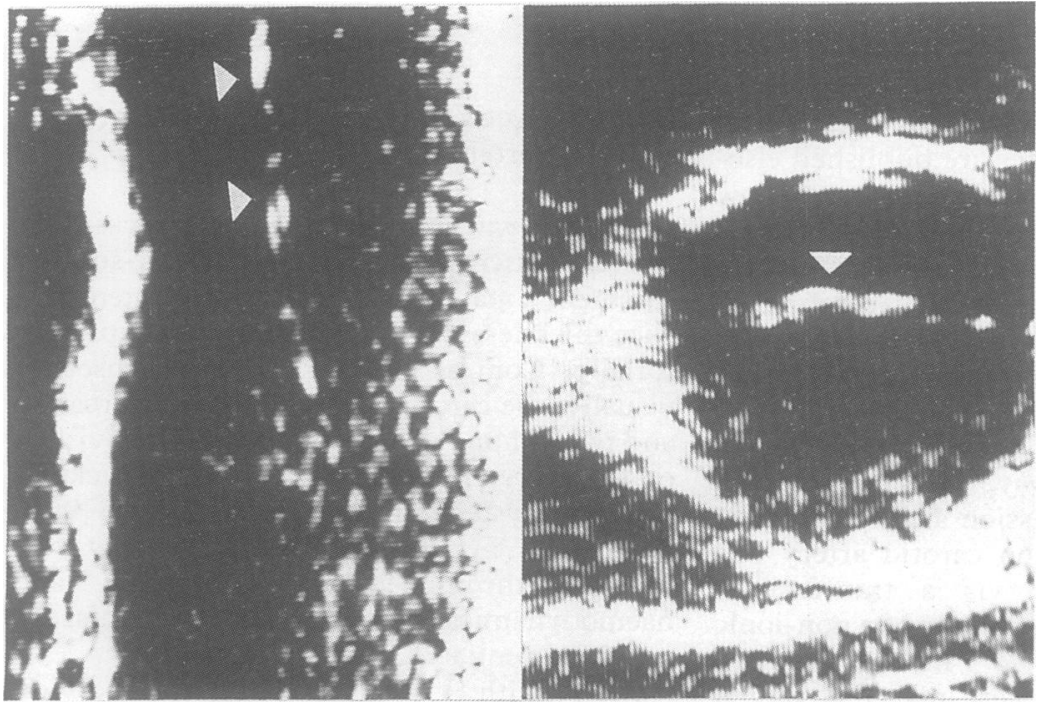

Figure $3 B$-mode imaging of ICA dissection in longitudinal (left) and transversal (right) views. Intimal flap (arrows) oscillated within blood stream. all of them with premonitory attacks. One patient had suffered transient ischaemic attacks (TIA), five had prolonged reversible ischaemic neurological deficits with preceeding TIA in three of them. While eight patients only had ischaemic events without any accessory symptom, one presented with accessory signs onlythat is, she had pulsatile tinnitus, carotidynia and temporal headache. Thus the combination of both was present in four of the 13 patients. Four patients complained only of pain located either temporally, retro-orbitally, or in the submandibular and carotid region. Another patient showed involvement of more than one cranial nerve presenting with trigeminal dysaesthesia, pulsatile tinnitus, and Horner's syndrome. All patients underwent therapeutical heparinisation with PTT 2 to 3 times normal control. Initial and follow up findings are summarised in the table.

\section{TECHNICAL FINDINGS}

Extracranial cw-Doppler sonography performed in 11 patients before cerebral arteriography showed a high-grade ICA stenosis retromandibularly at least $2 \mathrm{~cm}$ distal to the bifurcation in six cases. This finding was thought to be characteristic of an ICA dissection in terms of type and location of the lesion. Four other patients showed to-and-fro movement of the blood column in the proximal ICA, possibly indicative of a blind arterial stump due to complete occlusion of the distal ICA. ${ }^{719}$ Only a tentative diagnosis of ICA dissection was made in these patients as similar findings may also be seen in embolic ICA occlusions. In one case a $90 \%$ ICA stenosis was detectable immediately at the carotid bifurcation, suggesting arteriosclerotic disease rather than dissection. During submandibular insonation of the ICA by means of transcranial Doppler sonography each of the seven extracranial stenotic lesions could be traced further distally, some of them even extending up to the pars petrosa of the carotid artery. The typical sonographic finding was a high-flow velocity signal and post-stenotic disturbed flow indicated by bidirectional low frequency components of the flow signal (fig 2). In three cases, pronounced harmonic post-stenotic covibrations of the affected vessel wall segments generated so-called "musical murmurs". ${ }^{20}$ In two patients an intracarotid valve mechanism with functional ICA occlusion and stoppage of flow 


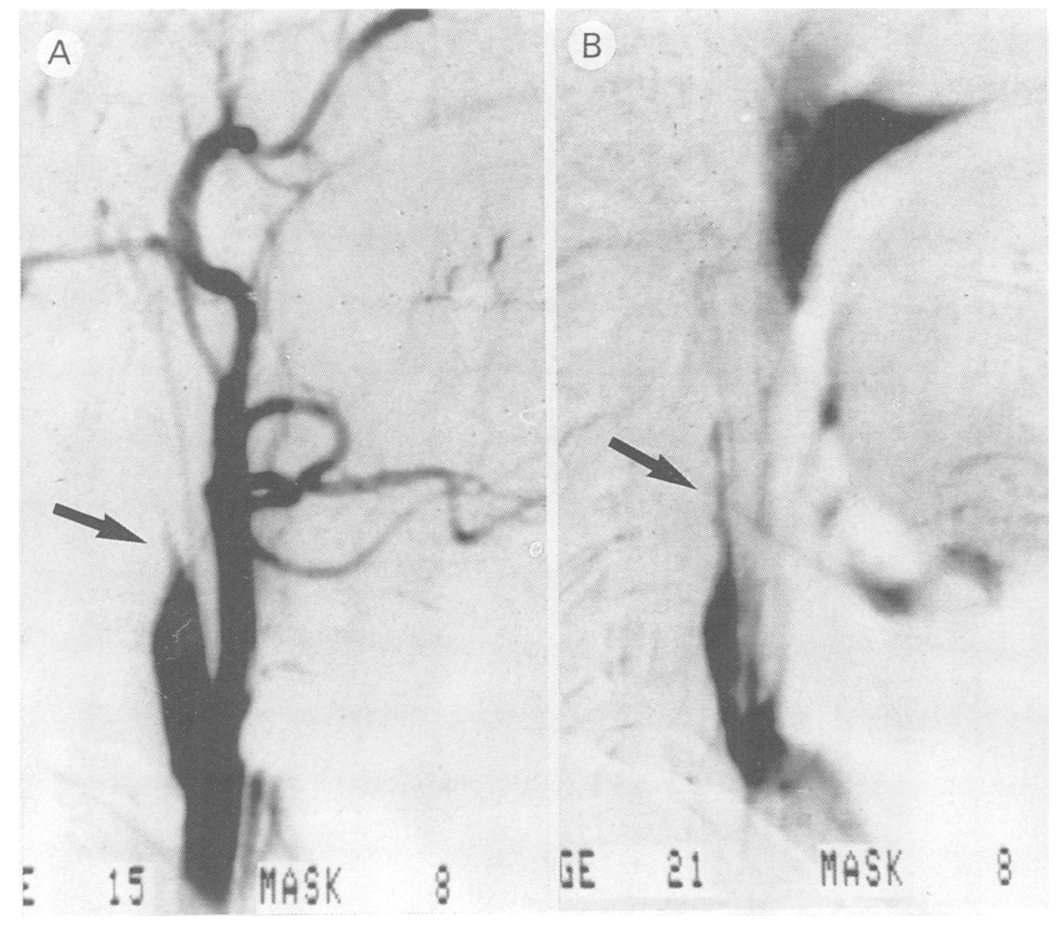

Figure 4 Typical angiographic appearance of ICA dissections. (a/b) Gradually tapering ICA occlusion (arrows) during early and late phase of angiogram. (c) Long filiform ICA stenosis exceeding $2 \mathrm{~cm}$ in length at base of skull (arrows) and pseudoaneurysmatic dilatation of artery (arrow head).

during diastole but a short-lasting jet-like flow signal during systole could be detected. During the additional transtemporal insonation of the middle cerebral artery in nine patients, lowflow became obvious in five cases.

B-mode sonography of the ICA in the neck was performed in five cases. A false lumen with an intimal flap could be shown in only one of them (fig 3). In the other cases the carotid bifurcation and the proximal 1 to $2 \mathrm{~cm}$ of the ICA appeared normal. In two cases flow signal within the proximal ICA appeared abnormal with lack of diastolic or even reversed blood flow indicating high peripheral resistance. These patients turned out to have either a distal ICA occlusion or a pseudo-occlusion. An initial arteriography was performed after ultrasound investigations in 11 patients within 24 hours after admission and in two within the first two weeks. Angiograms showed five ICA occlusions, four of them with the typical gradually tapering appearance of the proximal stump (fig 4a, b). Eight ICA stenoses of variable extent were also seen (fig 4c). Four of them had an extraluminal pouch of contrast medium close to a tight stenosis beyond the base of the skull. In the other cases the appearance of the lesions was also suggestive of but less specific for ICA dissection, and final diagnosis was based on the rapid resolution of the lesion during follow up. Angiograms were in accordance with Doppler sonography findings in every case. The type of vessel lesion (occlusion $v$ stenosis) did not correspond to certain clinical symptoms or the severity of the deficits.

Brain imaging by means of cranial CT showed low flow infarctions in five and thromboembolically induced territorial infarctions in six cases, ${ }^{18}$ but was normal in two. (Details are

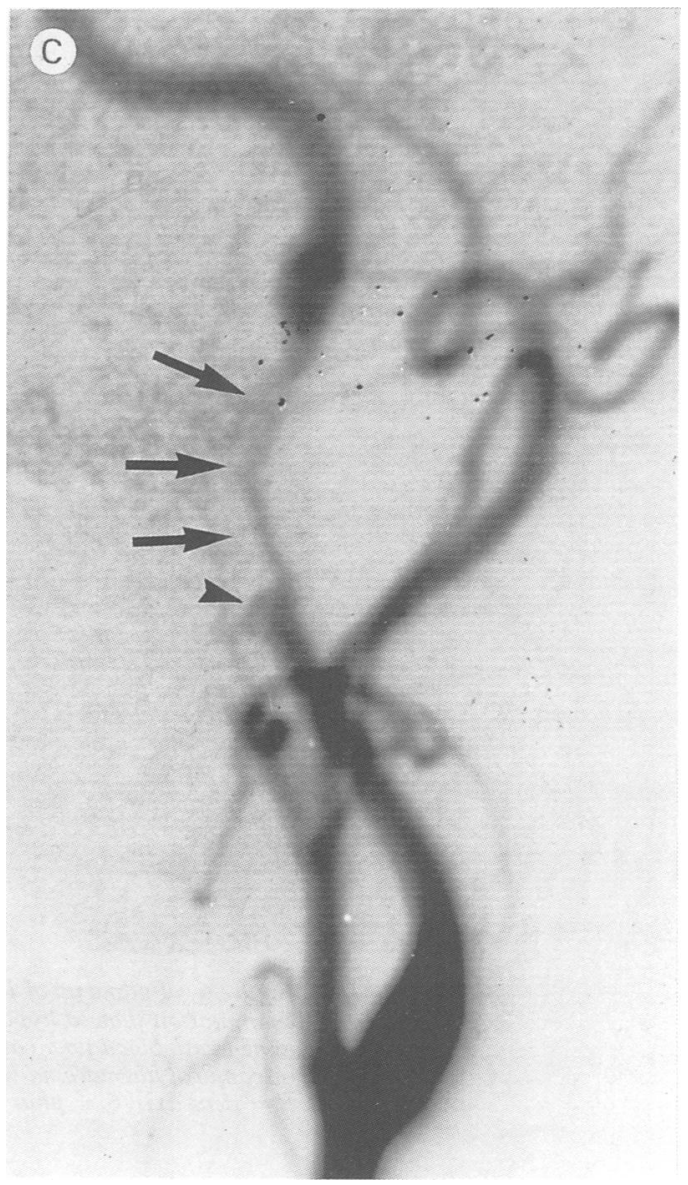

published elsewhere ${ }^{21}$ ). The type and extent of brain infarctions did not depend on the type of vessel lesion.

Direct imaging of the affected carotid artery by means of contrast enhanced CT revealed highgrade lumen narrowing in only two cases. Both ultrasound and arteriography were confirmative. In five patients dissection of the artery

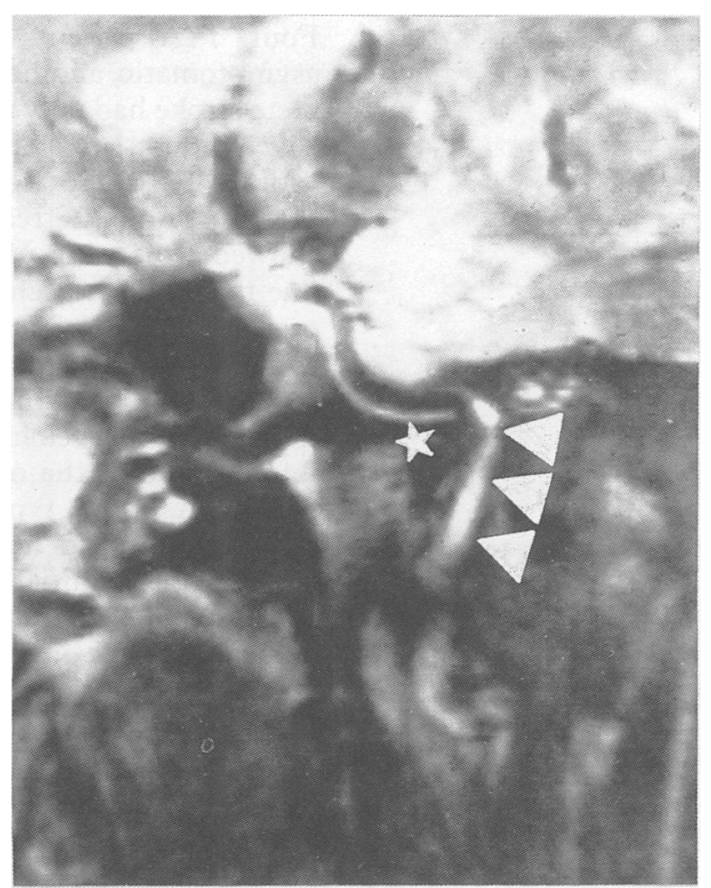

Figure 5 T2-weighted paraxial image of ICA dissection. Hyperintense vessel wall signal (arrow heads) beyond pars petrosa of skull (asterisk) is abnormally broad and indicates intramural haematoma. 


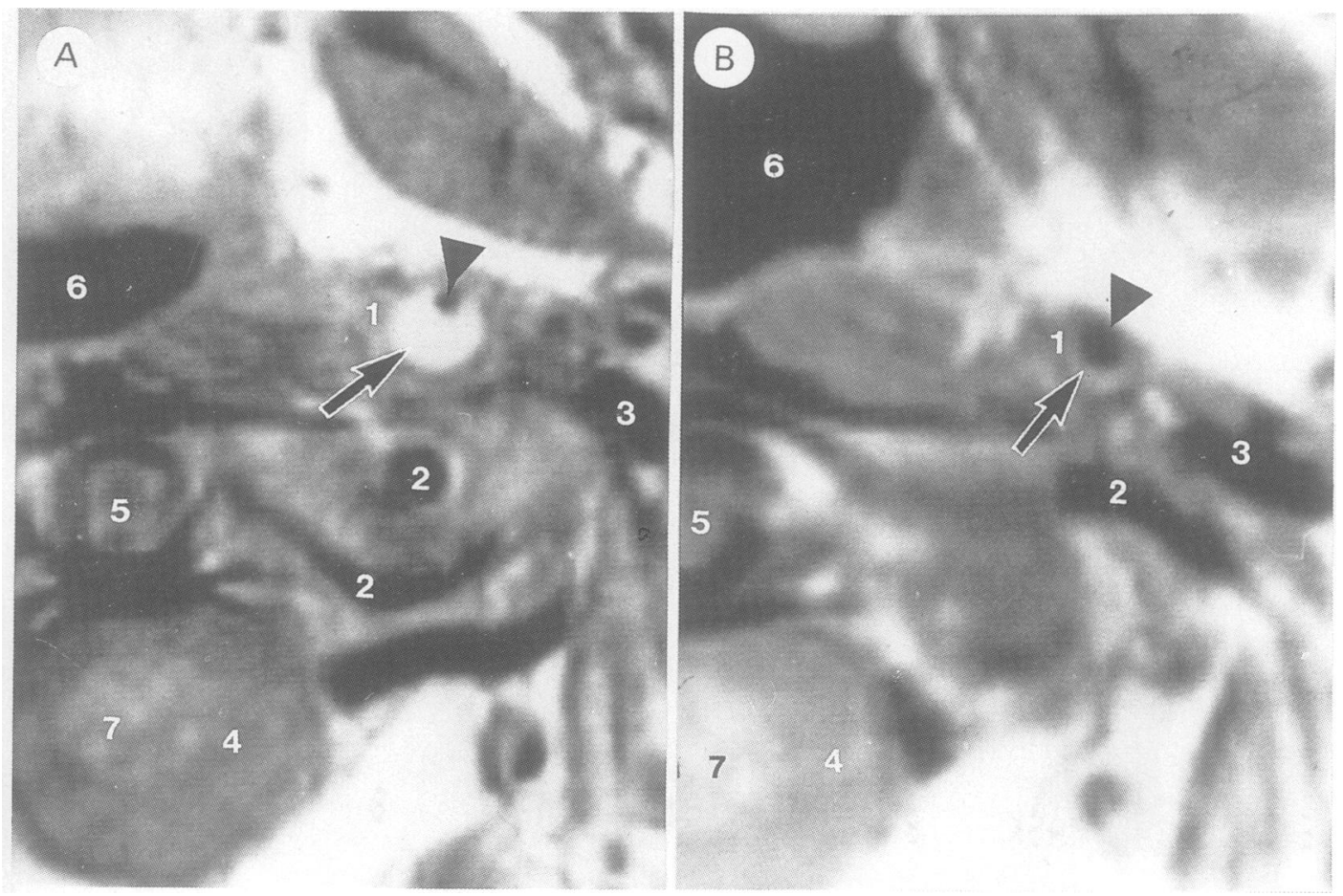

Figure 6 Follow up of ICA dissection by means of MRI imaging (T2-weighted, horizontal cut). (a) Initial examination showed hyperintense sickle-like vessel wall haematoma (arrow) leaving only small residual, hypointense lumen with blood flow (arrowhead). (b) Two weeks later, ICA lumen (arrowhead) nearly restored by resorption of intramural haematoma (arrow). $1=$ internal carotid artery, $2=$ vertebral artery, $3=$ jugular vein, $4=$ spinal fluid, $5=$ dens axis, $6=$ pharynx, $7=$ medulla.

could be pinpointed directly by MRI. The intramural haematoma presented as a hyperintense vessel wall signal in both T1- and T2weighted images (fig 5). Again, findings were in accordance to Doppler sonography and arteriography.

\section{CLINICAL AND LABORATORY FOLLOW UP FINDINGS}

Four TIA patients subsequently remained asymptomatic, another four patients with complete stroke had only minimal residual deficits. Five patients remained considerably handicapped by their ischaemic deficit. During the course of the treatment, only one patient showed worsening of the neurological deficit due to complete occlusion of an initially stenosed ICA. Transcranical Doppler sonography showed normalisation in seven cases or, at least, severe reduction of the lesions in five cases. The degree of improvement did not depend on the initial grade of the occluding lesions. In one patient the initial typical occlusion proved by arteriography did not improve. In only one patient did the initial $80 \%$ stenosis progress to an occlusion. There was no relation between clinical outcome or angiological follow up findings and the initial severity of the ICA lesion. Day by day transcranial Doppler studies also revealed rapidly improving intracerebral haemodynamics paralleling ICA blood flow normalisation. Repeat angiography in four patients showed normalisation of the vessel lumina. In four other cases follow up studies by MRI also showed normalisation of the vessel wall (fig 6) corresponding to the transcranial Doppler findings.

\section{Discussion}

We studied 13 patients with isolated ICA dissection by means of a battery of noninvasive and invasive tests. The causes of the vessel lesion were whiplash injury of the neck and questionable blunt trauma in four patients, the remainder suffering from idiopathic spontaneous ICA dissections. In no patient did arteriography deliver indications for fibromuscular dysplasia, Marfan's syndrome, or cystic medionecrosis as the underlying vessel disease. ${ }^{22-27}$ Hypertension, cigarette smoking, migraine, and contraceptive pills are thought to be risk factors for ICA dissections ${ }^{28}$ and were present in eight of our patients. In one patient, however, the dissection may have been atherosclerotic in origin, as arteriograms showed an ulcerated atherosclerotic plaque immediately next to the proximal end of the tapering stenosing dissection; while the latter disappeared, the plaque remained. Clinically the combination of an acute stroke including TIA with so called accessory symptoms, like Horner's syndrome, pulsatile tinnitus, temporal pain, and carotidynia, strongly suggests an underlying ICA dissection. ${ }^{1} 910141528-31$ Just one third of our patients, however, showed this combination of symptoms, suggesting why the true nature of the initial signs may be overlooked and that technical investigations are necessary to lead to the correct diagnosis.

Up to now carotid arteriography was thought to be mandatory for the diagnosis of ICA dissection. ${ }^{1-3}$ Findings thought diagnostic ${ }^{32}$ are an extraluminal pouch filled with contrast material; a double lumen; a smooth or scallopped narrowing of the ICA distal to the 
carotid sinus; a long filiform stenosis exceeding $2 \mathrm{~cm}$ in length; and a gradually tapered occlusion. Some of these signs, however, are less specific and do not unequivocally prove an ICA dissection in every case. ${ }^{12273233}$ Only eight of our 13 patients showed arteriographically pathognomonic tapering occlusion or long filiform stenosis. Other findings were suspicious but in these cases follow up findings proved the diagnosis correct. There is a need for diagnostic tools which are both non-invasive and reliable as arteriography during the acute phase bears a substantial risk of embolic complications. ${ }^{35}$ Extracranial Doppler sonography, which was performed in 11 cases, showed a retromandibular high grade stenosis of a typical finding in most of the cases. The site and type of this lesion is highly suggestive of ICA dissection, particularly in the young and if risk factors or signs of atherosclerosis are lacking. Flow abnormalities indicating a blind ICA stump suggest ICA occlusion distal to the bifurcation. This finding is less conclusive as to the underlying vascular disease ${ }^{11}$ but rather suggests dissection than distal embolic ICA occlusion. Atherothrombotic ICA occlusion at this site is rare. $^{35}$

Transcranial Doppler sonography turned out to be a sensitive technique for detecting arterial disease inaccessible to conventional Doppler tests ${ }^{36}$ and provided quite characteristic findings for detecting ICA dissection. Stenoses were identified in all cases. The location of the lesions, either stenosis or occlusion, was also highly suggestive for the diagnosis. There was no false positive finding, although there were too few cases for statistical analysis. Definite proof of the diagnosis might be achieved during repetitive TCD tests in that both stenoses and occlusions had a strong tendency to improve over time. ${ }^{1}$ Day by day ultrasound checks demonstrated rapid ICA recanalisation in all but one case. A systolic valve mechanism with transient occlusion of the distal ICA during diastole also seems to be a specific TCD finding as to our knowledge it has not been described as a transient phenomenon in atherosclerotic ICA stenoses or pseudoocclusions. ${ }^{37}$ ICA dissections were also found to have considerable impact on intracranial haemodynamics in that reduced intracranial perfusion pressure led to severe slowing of blood flow velocity. ${ }^{21}$ Duplex scanning allows for rapid visualisation of ICA in the neck by Bmode imaging. There are, however, limitations of this technique. Due to the distal localisation of the lesions ${ }^{173233}$ the characteristic intimal flap may be shown only in a limited number of patients; we succeeded in only one out of five patients. Sector scanners with small transducers have been reported to be more sensitive for detecting a dissected ICA wall..$^{4-9}$

Early MRI was performed in five cases and led to the correct diagnosis in all of them, as was proven by simultaneous arteriography in four cases and by angiological follow up investigations in all. The intramural haematoma was indicated by a hyperintensive arterial wall signal on both $\mathrm{T} 1$ - or proton-weighted and $\mathrm{T} 2$ weighted images, as has been reported by others. " Other stenosing processes like fibromuscular dysplasia, vasculitis, or atherosclerosis may also be differentiated by MRI. ${ }^{14} 15$ The false vessel lumen can directly be visualised and separated from the flowing blood column in both the residual and false lumen. ${ }^{11}$ In our study, five initial and four follow up studies of ICA dissections exactly corresponded in site and severity to Doppler and angiographic findings, indicating the high diagnostic reliability and validity of this technique. In contrast, enhanced CT imaging of ICA in the neck, as a rule, did not prove to be diagnostic.

The diagnosis of an ICA dissection is undoubtedly confirmed by rapid day by day regression of the arterial lesion. ${ }^{133} \mathrm{We}$ showed this by monitoring lesions by close-meshed, repetitive transcranial Doppler sonography studies. This is also true for progression of a stenosis, which eventually may occur. Repeat MRI scans in four cases also showed normalised or nearly normalised arteries. Whether treatment with therapeutic heparinisation or antiplatelet agents will prompt a better outcome is still a matter of debate. ${ }^{12922} 233239$ Interestingly, infarctions due to carotid artery dissections are as commonly thromboembolic in origin as haemodynamic. ${ }^{21}$ This may influence the type of treatment.

In conclusion, patients with acute strokes, particularly the young, and those presenting with accessory symptoms should be subjected to intense extracranial and transcranial ultrasound checks by means of ECD, TCD, and, if available, B-mode imaging. The submandibular approach of transcranial Doppler sonography is most promising, the characteristic finding in ICA dissection being an extended distal stenosis. In the case of distal extracranial ICA occlusion, with proximal "blind stump" phenomenon, the diagnosis is highly suggestive. Follow up ultrasound examinations often deliver further diagnostic clues as dissections tend to regress (or progress) rapidly. Findings may be further clarified by means of MRI as it may demonstrate the underlying vessel wall disease. Both procedures are non-invasive, reliable, and quick. From our point of view, arteriography should be confined to certain cases in the post-acute period when regression of the lesion has already taken place. At this time, residual aneurysmata spuria may be found, which require surgical removal. ${ }^{30}$ Based on our experiences, four further cases of ICA dissection have been diagnosed non-invasively by both transcranial Doppler sonography and MRI. Follow up findings strongly suggested the diagnosis to be correct.

We are greatly indebted to Christiane Goebel-Dizinger, Gabi Tietz, Waltraud Schumacher, and Vera Schappeler, vascular technicians, for considerable technical assistance.

1 Hart RG, Easton JD. Dissections of cervical and cerebral arteries. In: Barnett HSM, ed. Neurologic clinics vol 1. arteries. In: Barnett HSM, ed. Neurologi
Philadelphia: WB Saunders, 1983:155-82.

2 Mokri B, Sundt TM, Houser OW, Piepgras DG. Spontaneous dissection of the cervical internal carotid artery. Ann Neurol 1986;19:126-38.

3 Petro GR, Witwer GA, Hodge CJ, Bredenberg CE, Jastremski MS, Kieffer SA. Spontaneous dissection of the cervical internal carotid artery: correlation of arteriography, CT 
and pathology. $A J R$ 1987;148:393-8.

4 deBray JM, Dubas F, Joseph PA, Causeret H, Pasquier JP, Emile J. Etude ultrasonique de 22 dissections carotidiennes. Rev Neurol 1989;145:702-9.

5 Kaps M, Dorndorf W, Damian MS, Agnoli L. Intracranial hemodynamics in patients with spontaneous carotid dissection: transcranial ultrasound follow-up studies. Eur Arch Psychiatr Neurol Sci 1990; in press.

6 Kotval PS, Babu SC, Cozzi A, Barakat K. Role of the intimal flap in arterial dissection: sonographic demonstration. flap in arterial dissectio

7 Ringelstein EB. Continuous-wave doppler sonography of the extracranial brain-supplying arteries. In: Weinberge J, ed. Noninvasive imaging of cerebrovascular disease. New York: Alan R Liss, 1989:27-48.

8 Rohr J, Gauthier G. Hématomes disséquants spontanés successifs à 3 ans et demi d'intervalle des deux artères carotides internes. Rev Neurol 1987;143:115-20.

9 Steinke W, Aulich A, Hennerici M. Diagnose und Verlau von Carotisdissektionen. Dtsch Med WSchr 1989;114:1869-75.

10 Bogousslavsky J, Despland PA, Regli F. Spontaneous carotid dissection with acute stroke. Arch Neurol 1987;44:137-40.

11 DalPozzo G, Mascalchi M, Fonda C, Cadelo M, Ronchi O, Inzitari $D$. Lower cranial nerve palsy due to dissection of the internal carotid artery: CT and MR imaging. J Comput the internal carotid artery: CT
Assist Tomogr 1989;13:989-95.

11 Heinz ER, Pizer SM, Fuchs H. Examination of the extracranial bifurcation by thin-section dynamic CT: direct visualization of intimal atheroma in man. AJNR 1984;5:355-9.

13 Lubbers DJ, Tomsick TA. CT demonstration of spontaneous internal carotid artery dissection. $J$ Neurosur 1985;63:792-3.

14 Goldberg HI, Grossman RI, Gomori JM, Asbury AK, Bilaniuk LT, Zimmerman RA. Cervical internal carotid artery dissecting hemorrhage: diagnosis using MR. Radiology 1986;158:157-61.

15 Lieschke GJ, Davis S, Tress BM, Ebeling P. Spontaneous internal carotid artery dissection presenting as hypoglossal nerve palsy. Stroke 1988;19:1151-5.

16 Ringelstein EB. A practical guide to transcranial Dopplersonography. In: Weinberger J, ed. Noninvasive imaging of cerebrovascular disease. New York: Alan R Liss, 1989. 75-121.

17 Ringelstein EB, Koschorke S, Holling A, Thron A, Lambertz $\mathrm{H}$, Minale C. Computed tomographic patterns of proven embolic brain infarctions. Ann Neurol 1989;26:759-65.

18 Ringelstein EB, Zeumer H, Angelou D. The pathogenesis of strokes from internal carotid artery occlusion. Diagnostic and therapeutical implications. Stroke 1983;14: 867-75.

19 Reutern von GM. Free hand Doppler techniques for the examination of the extracranial arteries with continuous wave Doppler. In: Spencer MP, ed. Ultrasonic diagnosis of cerebrovascular disease. Doppler techniques and pulse echo imaging. Dordrecht, Boston, Lancaster: Martinus Nijhoff, 1987:157-77.

20 Aaslid $R$, Nornes $H$. Musical murmurs in human cerebral arteries after subarachnoid hemorrhage. J Neurosurg
1984;60:32-6.

21 Weiller C, Müllges W, Ringelstein EB, Büll U, Biniek R, Reiche W. Patterns of brain infarctions in internal carotid artery dissections. Neurosurg Rev 1991;14:111-13.

22 Anderson CA, Collins GJ jr, Rich NM, McDonald PT Spontaneous dissection of the internal carotid artery associated with fibromuscular dysplasia. Am Surg 1980;46:263-6.

23 Correll JW, Quest DO, Carpenter DB. Nonatheromatous lesions of the extracranial cerebral arteries. In: Smith RR, ed. Stroke and the extracranial vessels. New York: Raven Press, 1984:312-31.

24 Mettinger KL. Fibromuscular dysplasia and the brain current concept of the disease. Stroke 1982;13:53-8.

25 Osborne AG, Anderson RE. Angiographic spectrum of cervical and intracranial fibromuscular dysplasia. Stroke 1977;8:617-26.

26 Austin MB, Schaefer RF. Marfan's syndrome with unusual blood vessel manifestations: primary medionecrosis dissection of right innominate, right carotid, and left carotid arteries. Arch Pathol 1957;64:205-9.

27 Luken MG III, Ascherl GF jr, Correll JW, Hilal SK Spontaneous dissecting aneurysms of the extracranial Spontaneous dissecting aneurysms of the extracrania

28 Shuster $E$, Mokri B, Sundt TM, Houser OW, Piepgras D. Spontaneous dissection of the internal carotid arteries: clinical presentation, angiographic features and outcome. Neurology 1985;35:suppl 1:212.

29 Goodman JM, Zink WL, Cooper DF. Hemilingual paralysis by spontaneous carotid artery dissection. Arch Neurol 1983;40:653-4.

30 Mokri B, Piepgras DG, Houser OW. Traumatic dissections of the extracranial internal carotid artery. $J$ Neurosurg 1988;68:189-97.

31 West TET, Davies RJ, Kelly RE. Horner's syndrome and headache due to carotid artery disease. $\mathrm{Br}$ Med $1976 ; 1: 818-20$,

32 Fisher CM, Ojemann RG, Robertson GH. Spontaneous dissection of cervico-cerebral arteries. Can Neurol Sci 1978;5:9-19.

33 O'Dwyer JA, Moscow N, Trevor R, Ehrenfeld WK, Newton TH Spontaneous dissection of the carotid artery. ton TH. Spontaneous dissect
Radiology 1980;137:379-85.

34 Rieger P, Piepgras U. Nebenwirkungen und Komplikationen bei neuroradiologischen Kontrastuntersuchungen. RöPraxis 1984;37:89-98.

35 Hass WK, Fields WS, North RR, Kricheff II, Chase NE Bauer RB. Joint study of extracranial arterial occlusion. JAMA 1968;203:159-66.

36 Ley-Pozo JA, Ringelstein EB. Noninvasive detection of occlusive disease of the carotid siphon and middle cerebral artery. Ann Neurol 1990;20:640-7.

37 Ringelstein EB, Berg-Dammer E, Zeumer H. The so-called atheromatous pseudoocclusion of the internal carotid artery. A diagnostic and therapeutical challenge. Neuroradiology 1983;25:147-55.

38 Kapp JP, Smith RR. Spontaneous resolution of occlusive lesions of the carotid artery. J Neurosurg 1982;56:73-9.

39 Biller J, Hingtgen WL, Adams HP jr, Smoker WRK, Godersky JC, Toffol GJ. Cervicocephalic arterial dissections. Arch Neurol 1986;43:1234-8. 